\title{
Development of a polyurethane sealing gasket with excellent sealing and opening properties
}

\author{
Toshinori Moriga ${ }^{1,2}$, Naoki Aoyama ${ }^{3}$ and Keiji Tanaka ${ }^{1}$
}

\begin{abstract}
Alternative materials to replace the currently used poly(vinyl chloride) (PVC) plastisols as sealing gaskets for use in wide-mouth glass jars have been desired. In this study, we propose a novel urethane-based polymer as a better replacement for PVC plastisols. This polymer was prepared by reacting a diol with a molecular weight (MW) of $1000 \mathrm{~g} \mathrm{~mol}^{-1}$, a triol with an MW of $500 \mathrm{~g} \mathrm{~mol}^{-1}$ and an aliphatic diisocyanate adduct with $\mathrm{MW}$ of $430 \mathrm{~g} \mathrm{~mol}^{-1}$. When additives, such as hollow particles as a blowing agent and lubricants, were incorporated into this urethane polymer, the resulting material exhibited a rubbery plateau with a low modulus over a wide temperature range, from a temperature $<0{ }^{\circ} \mathrm{C}$ to a temperature $>100{ }^{\circ} \mathrm{C}$. These properties favorably support this material for use as a sealing gasket owing to its remarkable sealing and opening characteristics. Polymer Journal (2015) 47, 400-407; doi:10.1038/pj.2015.6; published online 4 March 2015
\end{abstract}

\section{INTRODUCTION}

Metal caps such as twist-off caps and screw caps used for bottled products need a suitable sealing gasket for effective sealing to close and efficient release to open. In the case of a twist-off cap, four claw-like projections, called lugs, can be found at the open end. The cap can be opened and closed with a small rotation angle of $15^{\circ}$ against four noncontinuous threads formed on the neck part of a bottle opening. Figure 1 shows a picture of twist-off caps. A rubber-like sealing gasket is formed on a metal shell upon closure to seal the bottle. The two properties of sealing and release, inherently opposite to each other, are particularly challenging to incorporate in a material. Poly(vinyl chloride) (PVC) gaskets have been widely used to meet this requirement. However, these gaskets pose an issue of undesirable migration of plasticizers contained in the material to the content of the bottled products for which they are used. ${ }^{1-10}$ Thus, alternative materials to replace these PVC gaskets are desired not only for food containers but also for a much wider range of applications. ${ }^{11-16}$

To achieve an excellent sealing property, the material used as a gasket should possess a low and constant elastic modulus under a wide range of temperatures. In addition, stress relaxation or a creep deformation should not occur in the contact area between the gasket and the bottle mouth. To maintain an effective seal, the material must have an appropriate elasticity when it undergoes deformation recovery. This allows the gasket to properly align with the surface of the bottle opening without being detached. On the other hand, a wide contact area or a compressive stress between the sealant and the bottle mouth becomes an impediment to the opening property. Hence, balancing these two opposing requirements in a material poses a challenge.

Because bottled products are subjected to a high temperature for sterilization, the pressure inside these products becomes subatmospheric at room temperature. The pressure difference between the inside and the outside of the bottle strongly presses the sealant to the bottle mouth and makes opening difficult. Polar polymers such as PVC and polyurethane possess a larger surface energy, resulting in an attractive interaction with glass in comparison with a polyolefin sealant. This leads to a larger frictional resistance during opening compared with nonpolar polymers. Thus, to improving the opening property, solid and/or liquid lubricants such as fatty acid amides and/ or silicones need to be added in the surface region of the sealing gasket. This can remarkably reduce the frictional resistance between the sealant and the bottle mouth. Of course, it is also important that the lubricants stay in the surface region during use.

In this study, we successfully prepared a novel urethane-based polymer with an excellent sealing property by crosslinking terminalfunctional oligomers (telechelic molecules), composed of a polyisocyanate (NCO group) and a polyol compound ( $\mathrm{OH}$ group), with a controlled molecular weight (MW) and composition. The urethanebased polymer exhibited a rubbery plateau with a low modulus in a wide temperature range and had a reduced plastic flow under a compressive stress. These properties meet the requirements for an effective sealing gasket. ${ }^{17-19}$ We also investigated the effects of using additives such as lubricants and blowing agents to balance the sealing and opening properties of the sealing gasket.

\section{EXPERIMENTAL PROCEDURE}

Samples

The polyisocyanate used in this study was an adduct C-2612 (CAS 35901350-6) composed of hexamethylene diisocyanate (HDI) and 1,3-butyleneglycol $(1,3-B G)$ and made by Nippon Polyurethane Industry (Tokyo, Japan). It is a bifunctional pre-polymer with a molecular structure of HDI-[1,3-BG]-HDI and an MW of $430 \mathrm{~g} \mathrm{~mol}^{-1}$. Two types of polyols were used: (1) PTG-1000SN (CAS 2519013-50-6; Hodogaya Chemical (Tokyo, Japan)) and (2) P-1010NF

${ }^{1}$ Department of Applied Chemistry, Kyushu University, Fukuoka, Japan; ${ }^{2}$ R\&D Center, Toyo Kohan Co., Ltd, Kudamatsu, Japan and ${ }^{3}$ Toyo Seikan Group Holdings, Ltd, Tokyo, Japan Correspondence: Dr T Moriga or Professor K Tanaka, Department of Applied Chemistry, Kyushu University, 744 Motooka, Nishi-ku, Fukuoka 819-0395, Japan. E-mail: moriga.toshinori@toyokohan.co.jp or k-tanaka@cstf.kyushu-u.ac.jp

Received 13 August 2014; revised 10 December 2014; accepted 9 January 2015; published online 4 March 2015 
(CAS 39751-34-3; Kuraray Company, Ltd (Tokyo, Japan)). The former is a polytetramethylene ether glycol (PTMG) and the latter is a polyester polyol composed of adipic acid and 3-methyl-1,5-pentanediol. Both are bifunctional pre-polymers with an $\mathrm{MW}$ of $\sim 1000 \mathrm{~g} \mathrm{~mol}^{-1}$. As a crosslinking agent, or chain extender, F-510 (CAS 122310-07-0), a trifunctional polyol from Kuraray Company, Ltd, was used. It is a polyester polyol composed of adipic acid, 3-methyl-1,5-pentanediol and trimethylol propane and has an MW $\sim 500 .{ }^{19} \mathrm{P}-1010 \mathrm{NF}$ and $\mathrm{F}-510$ were specially prepared as prototype products for this study. It has been accepted that cold hardening occurs when PTMG is used as a soft segment. ${ }^{20}$ Chen et al. reported that soft segment crystallization was suppressed by the introduction of 3-methyl side groups into the PTMG backbone. ${ }^{21}$ We therefore attempted to restrict the cold hardening of PTMG through the use of aliphatic polyisocyanate adducts and polyester polyols with methyl pendants. Thus, the incorporation of methyl groups to the molecules plays an important role not only in the prevention of soft segment crystallization but also in the aging stability of the elastic modulus of the polymer, resulting in a stable flexibility of the crosslinked urethane polymer. Table 1 shows the chemical structures of the four components of the polyurethane: the polyisocyanate (C-2612) and polyols (PTG-1000SN, P-1010NF and F-510). As a reaction catalyst for urethanization, a di(n-octyl)tin maleate polymer, KS-1010A-1 (CAS 30173-13-8), purchased from Kyodo Chemical (Tokyo, Japan), was used. A hindered phenol antioxidant, IRGANOX1010, made by BASF (Ludwigshafen, Germany), was also used.

The following additives were used to prepare the sealing gasket: talc (SW-A), used as a filler and supplied by Asada Milling (Tokyo, Japan); titanium dioxide (Ti-PURE R902), used as a colorant and from DuPont (Wilmington, US-DE); and a lubricant prepared by mixing fatty acid amides, erucic acid and oleic acid amides (ALFLOW P-10 and ALFLOW E-10), from Nippon Oil \& Fats (Tokyo, Japan), with silicone oil (KF-96-1000CS and KF-96-300CS) from Shin-Etsu Chemical (Tokyo, Japan) and a blowing agent, the heat-expandable microcapsule EXPANCEL DU092-12022 (EXPANCEL, Technical Bulletin No. 29) from AKZO NOBEL (Amsterdam, Netherlands).

Table 2 summarizes the composition of the urethane-based polymer (TOYO-UR) and the urethane sealing gasket (UR1080). TOYO-UR was formed by the reaction between the polyisocyanate and the polyols in the presence of the catalyst and the antioxidant, as shown in Table 2. Sample sheets and

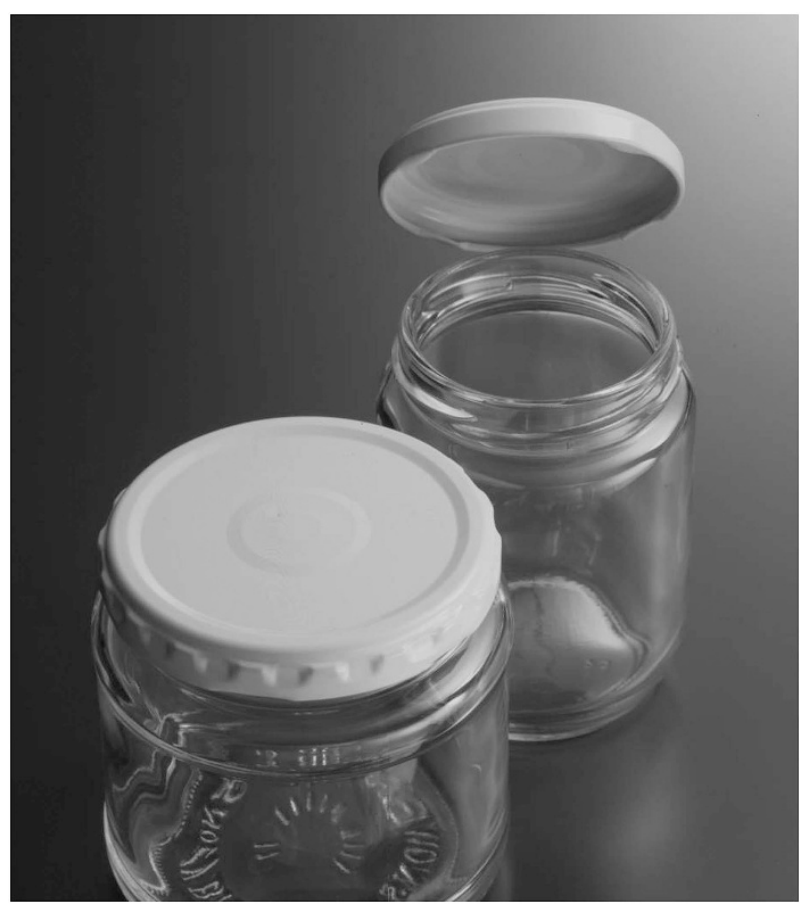

Figure 1 Twist-off caps and wide-mouth glass jars. A full color version of this figure is available at Polymer Journal online. closures were also prepared by curing the composition of the urethane sealing material (UR1080) under a certain condition. Here, the additives were first mixed with the polyols, resulting in a compound. Then, the polyisocyanate component was mixed into the compound with a molar ratio of $\mathrm{NCO} / \mathrm{OH}$ groups. ${ }^{23-26}$

\section{Mechanical properties}

Dynamic mechanical analyses (DMA) of the prepared materials were performed from -80 to $180^{\circ} \mathrm{C}$ at a frequency of $1.0 \mathrm{~Hz}$ and a heating rate of $3^{\circ} \mathrm{C} \mathrm{min}{ }^{-1}$ using a DMA6100 instrument from SII Nanotechnology. In addition to DMA, measurements of the JIS A hardness, compression set (\%) and Young's modulus were also performed following the test procedures described in JIS K 7312. The compression set was measured by loading a compressive strain of $25 \%$ at $70^{\circ} \mathrm{C}$ for $22 \mathrm{~h}$.

\section{Closure performance}

A sufficient amount of hot water $\left(80^{\circ} \mathrm{C}\right)$ was poured in glass jars. Then, they were sealed with twist-off caps in which the urethane sealing material (UR1080) was coated. The jars had mouth diameters $(\varphi)$ of $53 \mathrm{~mm}$. Then, the opening torque and the lateral force resistance were measured. Impact and unbalanced loading tests were conducted to determine whether leakage or suction occurred, respectively. In the impact test, a force of $1.13 \mathrm{Nm}$ ( $10 \mathrm{inch} \times$ pound) was applied onto a predetermined position of the closures with $\varphi$ of $53 \mathrm{~mm}$. In the unbalanced loading test, a similar evaluation was performed after applying an unbalanced force of $490 \mathrm{~N}$ per bottle ( $50 \mathrm{kgf}$ per bottle) on the samples for 1 week.

\section{RESULTS AND DISCUSSION}

PVC-based, styrene-based and olefin-based polymers have been widely used for sealing gaskets. We therefore began by conducting a dynamic mechanical analysis of these polymers. Panels (a), (b) and (c) of Figure 2 show the temperature dependence of the storage modulus $\left(E^{\prime}\right)$, loss modulus $\left(E^{\prime \prime}\right)$ and loss tangent $(\tan \delta)$ of these polymer samples at $1 \mathrm{~Hz}$. For comparison, the result for a model polyurethane network having a typical crosslinked structure, reproduced with permission, is shown in panel (d). ${ }^{27}$

The PVC elastomer was prepared by heating a plastisol composed of PVC particles and an epoxidized soybean oil. Its $E^{\prime}$ was relatively low in the temperature range from 0 to $80^{\circ} \mathrm{C}$. For this reason, PVC elastomers have been widely used as the material for the sealing gaskets of twist-off caps for wide-mouth jars. However, because a clear relaxation process existed at $\sim 0{ }^{\circ} \mathrm{C}$, the modulus could be drastically changed around the temperature, meaning that there may be a high risk of leakage upon drop impact at low temperatures. In addition, when the temperature increased beyond $110^{\circ} \mathrm{C}$, the modulus could be

Table 1 Chemical structures of the components in the urethane-based polymers

C-2612

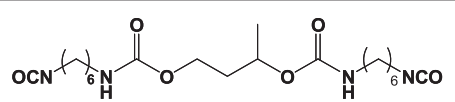

PTG-1000SN

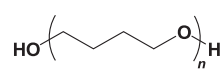

P-1010NF

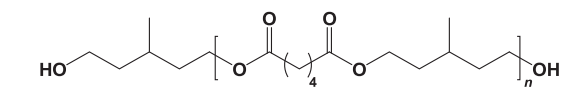

F-510

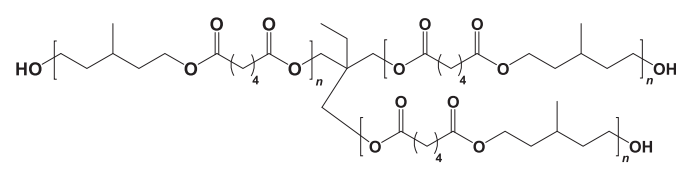


smaller than $1 \mathrm{MPa}$. Thus, it seemed that the PVC elastomer should not be used as a sealing material, especially when subjected to high temperature during sterilization. Although the modulus and heat resistance could be regulated using additives, the striking temperature dependence of the modulus still remained. Taking into account the conditions during the storage, distribution and sterilization of bottled foods, an effective sealing material requires that its modulus remains the same, especially at temperatures from 0 to $130^{\circ} \mathrm{C}$. Therefore, the modulus decrease by three orders of magnitude in this temperature region is undesirable; this is a critical weakness of the PVC elastomer as a sealing material.

In the case of a styrene-based gasket sample, the temperature dependence of its $E^{\prime}$ was relatively weaker than those of the PVC

Table 2 Composition of the urethane-based polymer (TOYO-UR) and the urethane sealing gasket (UR1080)

\begin{tabular}{lllc}
\hline Developed & Material type & Product name & Weight ratio (phr) \\
\hline Base & Polyisocyanate & C-2612 & 38 \\
Polymer: TOYO-UR & Polyols & PTG-1000SN & 41.3 \\
& & P-1010NF & 13.8 \\
& & F-510 & 6.9 \\
& Catalyst & KS-1010A-1 & 0.019 \\
Sealing gasket: & Antioxidant & IRGANOX1010 & 0.19 \\
UR1080 & Filler & SW-A & 15 \\
& Colorant & Ti-PURE R902 & 2 \\
& Lubricants & ALFLOW P-10 & 4 \\
& & ALFLOW E-10 & 4 \\
& & KF-96-1000CS & 1 \\
& & KF-96-300CS & 1 \\
\hline
\end{tabular}
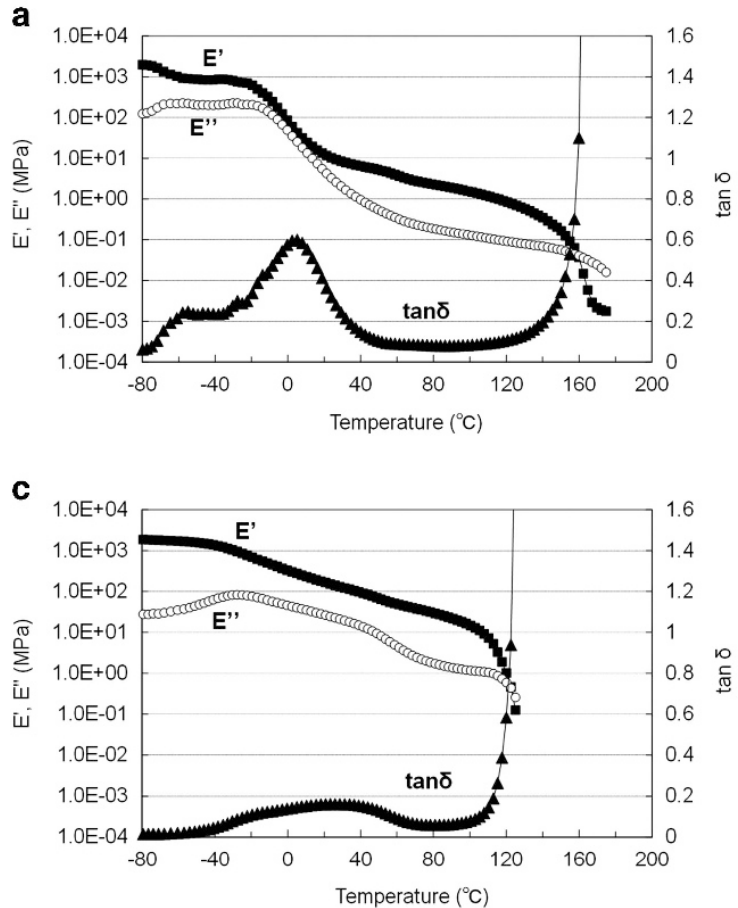

elastomer and an olefin-based one. The styrene-based elastomer was made of styrene-ethylene-butadiene-rubber with a small amount of mineral oil. The $E^{\prime}$ at $150{ }^{\circ} \mathrm{C}$ was $1.8 \mathrm{MPa}$, indicating that the elastomer had enough heat resistance to endure the harsh condition during retort sterilization. On the other hand, its $E^{\prime}$ near room temperature was greater than $10 \mathrm{MPa}$, which was a bit large for a sealing gasket. Thus, the styrene-based elastomer was not suitable as a sealing material for wide-mouth closures.

The olefin-based elastomer composed of an ethylene-propylenerubber (EPR) and a linear low-density polyethylene has been widely used as a sealing gasket for crown caps. The DMA measurement performed in a temperature range of -10 to $80^{\circ} \mathrm{C}$ showed that its $E^{\prime}$ changed from 500 to $30 \mathrm{MPa}$, as shown in panel (c) of Figure 2. In addition, the modulus rapidly decreased at $\sim 120^{\circ} \mathrm{C}$. Hence, it is not desirable to apply the olefin-based elastomer for heat-resistant applications. The high $E^{\prime}$ also posed a difficulty in balancing the sealing and opening properties required in sealing gaskets for bottled products.

As described above, the base polymers currently used as sealing gaskets were insufficiently effective within the temperature range of practical use. Thus, we focused on polyurethane as an alternative base polymer because it provided the opportunity for a low and constant modulus over a wide temperature range by regulating its crosslinked structures. Panel (d) of Figure 2 shows the dynamic viscoelastic properties of a model polyurethane composed of 2,4-toluene diisocyanate (2,4-TDI) as the diisocyanate, PTMG as the polyol and 3-methyl-1,5-pentanediol and trimethylol propane as the crosslinking agent. ${ }^{27}$ By introducing the crosslinked structure, a rubbery plateau was observed with $E^{\prime}$ of $10 \mathrm{MPa}$ or less in a wide temperature range $\left(10-200{ }^{\circ} \mathrm{C}\right) .{ }^{27}$ According to the kinetic theory of rubber elasticity, the Young's modulus $(E)$ at a low strain can be given by $3 \rho R T\left(1-2 M_{\mathrm{c}} /\right.$ $\left.M_{\mathrm{n}}\right) / M_{\mathrm{c}}$, where $\rho, \mathrm{R}, T, M_{\mathrm{c}}$ and $M_{\mathrm{n}}$ are the density, gas constant,
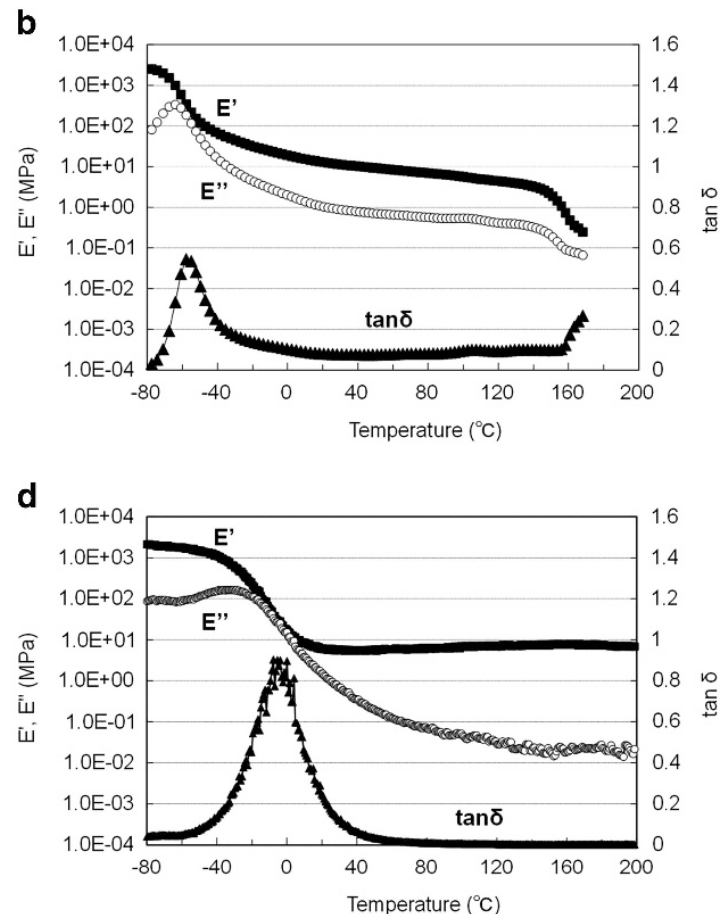

Figure 2 Dynamic viscoelastic properties as a function of temperature for various types of sealing materials. (a) PVC-based elastomer obtained from a PVC plastisol with epoxidized soybean oil as a plasticizer; (b) styrene-based elastomer: SEBS, styrene-ethylene-butadiene-rubber; (c) olefin-based elastomer: EPR, ethylene-propylene-rubber; and (d) crosslinked urethane elastomer composed of TDI, PTMG and TMP. ${ }^{27}$ 
absolute temperature, MW of the polymer segments between crosslinking points, and number-average MW of the polymer, respectively. ${ }^{28}$ When the crosslinking points were introduced into a polymer in its rubber-like region, $2 M_{\mathrm{c}} / M_{\mathrm{n}}$ became negligible, and then the rubbery plateau was obtained. Crystallization in this region inhibited a flatness of the plateau. The temperature dependence of $E^{\prime}$ is desirable for a base polymer of sealing gaskets. 2,4-TDI used here is an aromatic diisocyanate that generates an aromatic diamine upon reaction with water. Thus, as a material used in direct contact with food, 2,4-TDI is not appropriate in the manufacture of sealing gaskets because of health and safety concerns. ${ }^{29}$ Additionally, both 2,4-TDI and 3-methyl-1,5-pentanediol and trimethylol propane are low-MW substances. If they are used with PTMG to form an annular lining on a closure shell and then cured under a condition, which is similar to the conventional PVC plastisol, 2,4-TDI and 3-methyl-1,5-pentanediol and trimethylol propane will volatilize, resulting in abnormal foaming that poses problems related to appearance and performance. Furthermore, it is desired for the rubbery plateau to start at a much lower temperature.

To overcome the aforementioned problems, the following strategy was adopted. From a safety perspective, an aliphatic diisocyanate was used instead of an aromatic one. The abnormal foaming was solved by preparing a diisocyanate adduct and using pre-polymers as the polyol components. Using the diisocyanate adducts and the polymerized polyol pre-polymer lowered the concentration of functional groups in the polyurethane. This also led to an advantage in that the physical properties or chemical structure could be adapted as desired. ${ }^{30}$ Tables 1 and 2 show the structural formulas of the components and the composition of the urethane-based polymer, TOYO-UR, respectively.

Figure 3 shows the dynamic viscoelastic properties of TOYO-UR at $1 \mathrm{~Hz}$. Peaks of $E^{\prime \prime}$ and $\tan \delta$ were observed at -39 and $-25^{\circ} \mathrm{C}$, respectively. Low and constant $E^{\prime}$ values in the range of $5-10 \mathrm{MPa}$ were observed over a wide temperature range from -10 to $180^{\circ} \mathrm{C}$. This property favors the use of this material for sealing applications anywhere in the world, including in extreme climates such as a cold district, the temperate zones and the tropics. It should be mentioned that in the range of $\sim 10-140{ }^{\circ} \mathrm{C}, E^{\prime}$ slightly increased with increased temperature, showing entropy elasticity of an ideal rubber. ${ }^{28}$

Table 3 shows the functional values of the polyisocyanate and polyol (isocyanate value and hydroxyl value), average functional group numbers, MWs deduced based on the functional values and functional group numbers and molar ratios determined from the formulation shown in Table 2. Figure 4 provides the molecular design of the urethane-based polymer. $M_{\mathrm{c}}$ is the MW between crosslinking points, namely $\mathrm{X}$ in Figure 4 . The molecular design was to form a block,

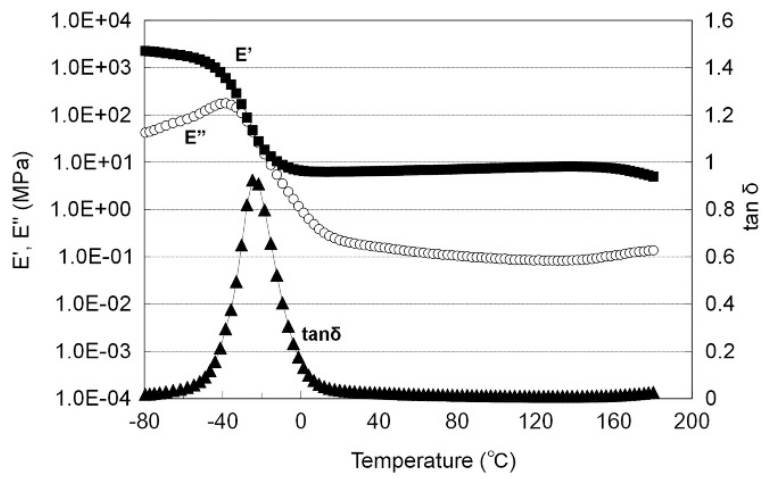

Figure 3 Dynamic viscoelastic property as a function of temperature for the urethane-based polymer (TOYO-UR) at $1 \mathrm{~Hz}$. which consisted of 3 units of component A, 2 units of component B and $2 / 3$ units of component $\mathrm{X}$ per 4 units of component $\mathrm{U}$. Component U corresponded to C-2612, component A corresponded to the mixture of PTG-1000SN and P-1010NF, and components B and $\mathrm{X}$ corresponded to F-510 in the same manner. It is clear that the $M_{\mathrm{c}}$ consisted of $4 \mathrm{~mol}$ of bifunctional polyisocyanate (C-2612), $3 \mathrm{~mol}$ of bifunctional polyol (PTG-1000SN and P-1010NF) and 2/3 mol of trifunctional polyol (F-510). Based on Table 3, the $M_{\mathrm{c}}$ value could be estimated to be $5070 \mathrm{~g} / \mathrm{mol}\left(=470^{*} 4+\left(960^{*} 0.75+950^{*} 0.25\right)^{*} 3+\right.$ $470 * 2 / 3)$

It has been widely accepted that the $M_{\mathrm{c}}$ value of a crosslinked rubber or an elastomer is given by $3 \rho R T / E .^{28,31}$ The Young's modulus at $25^{\circ} \mathrm{C}$, which is in the rubbery plateau region, determined by a tensile test was $1.5 \mathrm{MPa}$. Hence, the $M_{\mathrm{c}}$ value of TOYO-UR was calculated to be $5300 \mathrm{~g} \mathrm{~mol}^{-1}$, in good accordance with the designed value mentioned above.

Figure 5 shows the IR spectrum of the urethane-based polymer with peak assignments. A peak at $2270 \mathrm{~cm}^{-1}$, which was assigned to the NCO group, ${ }^{32}$ was discernible immediately after the reaction between $\mathrm{NCO}$ and $\mathrm{OH}$ groups. ${ }^{33,34}$ However, it disappeared after a while because of the reaction between remaining NCO groups and atmospheric moisture. ${ }^{33,34}$ The resultant amino groups also reacted with the remaining NCO groups, leading to the formation of urea linkages. ${ }^{33,34}$ It should be noted that peaks of urea and allophanate groups did not exist in the spectrum, meaning that the quantity of such functional groups was very small, if any. A broad peak at $3328 \mathrm{~cm}^{-1}$ assigned to the $\mathrm{NH}$ stretching vibration in the urethane linkage clearly appeared. On the other hand, the IR measurement of the polyols confirmed that a broad peak assigned to $\mathrm{OH}$ groups appeared at $3435 \mathrm{~cm}^{-1}$. However, because $\mathrm{OH}$ groups did not exist in TOYO-UR, it can be claimed that the broad peak at $\sim 3400 \mathrm{~cm}^{-1}$ arose from NH groups. Thus, the spectrum corresponded well to the reaction product shown in Figure 4 and indicated that the urethane reaction between the $\mathrm{NCO}$ and $\mathrm{OH}$ groups of the components proceeded as expected.

The urethane sealing gasket (UR1080) we proposed was obtained by blending additives into TOYO-UR, the urethane-based polymer, as stated in the experimental section and in Table 2. The additives were formulated to compensate for insufficient performances of the base polymer alone. For example, a lubricant and a blowing agent were added to compensate for the poor release (disengaging) property when the cap was removed from the bottle and for flexibility, respectively. The blowing agent was also used to reduce the cost of production.

Hollow particles, DU092-120, were used as the blowing agent. The outer shell of the particles was mainly made of acrylonitrile (AN) and methacrylonitrile (MAN), and liquid hydrocarbon was contained in the inside (EXPANCEL, Technical Bulletin No. 29). Once the UR1080 compound was heated, the urethane reaction proceeded to form the polyurethane. At the same time, the hydrocarbon inside the particles vaporized, resulting in a foam body of polyurethane. Figure 6 shows a cross-sectional image of a UR1080 foam body obtained by using scanning electron microscopy. Because the particle expansion depends on the heating condition, the amount of DU092-120 was adjusted to obtain a foam with the desired specific gravity.

Figure 7 shows a comparison between the viscoelastic properties of TOYO-UR and UR1080. The density of the TOYO-UR was 1.08 $\mathrm{g} \mathrm{cm}^{-3}$, whereas that of UR1080 was $0.72 \mathrm{~g} \mathrm{~cm}^{-3}$. Postulating that the foamed hollows in the urethane-based polymer are generated by chemical blowing, the $E^{\prime}$ of UR1080 should be lower than that of TOYO-UR. 
Table 3 Molecular weights and mole ratios calculated from functional values of the components in the polyisocyanate and polyols

\begin{tabular}{lccccc}
\hline $\begin{array}{l}\text { Components in } \\
\text { TOYO-UR }\end{array}$ & $\begin{array}{c}\text { Type of functional } \\
\text { group }\end{array}$ & $\begin{array}{c}\text { Functional value } \\
\left(\mathrm{mmol}^{-1}\right)\end{array}$ & $\begin{array}{c}\text { Functionality } \\
\text { (unit/molecule) }\end{array}$ & $\begin{array}{c}\text { Molecular weight } \\
\left(\mathrm{g} \mathrm{mol}^{-1}\right)\end{array}$ & $\begin{array}{c}\text { Mole ratio of the } \\
\text { composition }\end{array}$ \\
\hline C-2612 & NCO & 4.24 & 2 & 470 & 1.41 \\
PTG-1000SN & OH & 2.09 & 2 & 960 & 0.75 \\
P-1010NF & OH & 2.11 & 2 & 950 & 0.25 \\
F-510 & OH & 6.32 & 3 & 470 & 0.26 \\
\hline
\end{tabular}
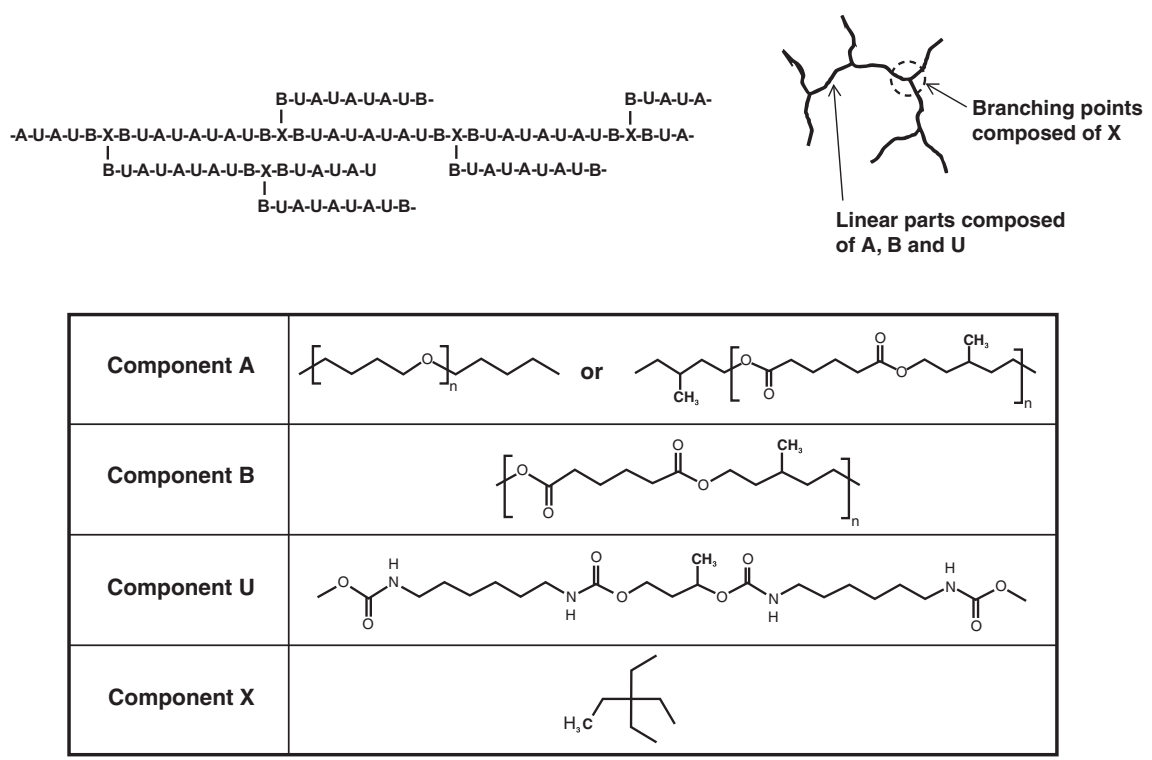

Figure 4 Model crosslinked structure of the urethane-based polymer (TOYO-UR).

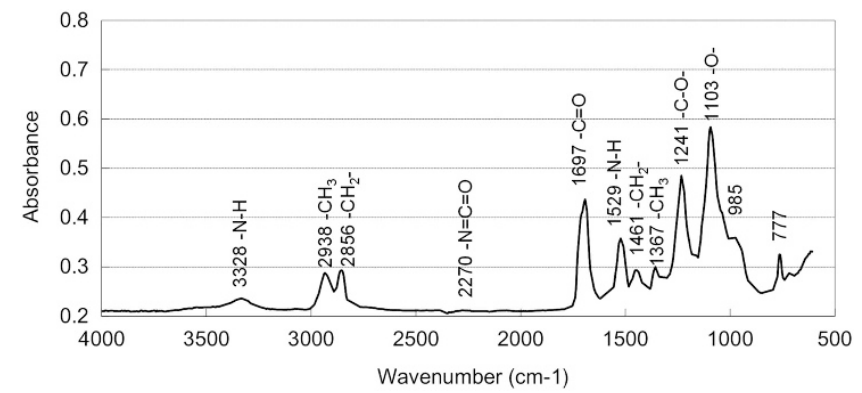

Figure 5 Infrared (IR) spectrum of the urethane-based polymer (TOYO-UR).

The $E^{\prime}$ value of UR1080 was larger than that of TOYO-UR in the temperature region near room temperature. When the temperature increased beyond the transition region, the $E^{\prime}$ of UR1080 decreased with increased temperature and eventually became lower than that of TOYO-UR. This decrease was probably because of the characteristic structure of the microcapsules. The outer shell of the microcapsules composed of AN and MAN was quite stiff in the lower temperature side of the rubbery plateau. However, as the temperature increased, the modulus of the outer shell decreased. That is, the shell began to soften in this temperature region (EXPANCEL, Technical Bulletin No. 29). This explains why the $E^{\prime}$ of UR1080 became lower than that of TOYO-UR at $\sim 110^{\circ} \mathrm{C}$. The $E^{\prime}$ of UR1080 at lower temperatures was also lower than that of TOYO-UR, probably because of the existence of independent air bubbles within the outer shell made from the AN-MAN copolymer in UR1080, as shown in Figure 6. Similarly, the $E^{\prime \prime}$ curve of UR1080 shifted to the low temperature region (less than $0^{\circ} \mathrm{C}$ ). On the other hand, the $E^{\prime \prime}$ of UR1080 showed a higher value than that of TOYO-UR at $0^{\circ} \mathrm{C}$. The polyurethane was in a rubbery state at $\sim 0{ }^{\circ} \mathrm{C}$ because its $T_{\mathrm{g}}$ was lower than $0{ }^{\circ} \mathrm{C}$. On the other hand, the outer shell composed of AN-MAN was in a glassy state because its $T_{\mathrm{g}}$ was much higher than $0{ }^{\circ} \mathrm{C}$. Such a situation induces $E^{\prime \prime}$ to be higher. Consequently, for TOYO-UR, the tan $\delta$ peak shifted to the lower temperature side and the peak height decreased because of the existence of the AN-MAN particles containing air. Moreover, a small $\tan \delta$ peak, which arose from the AN-MAN transition, appeared at $120^{\circ} \mathrm{C}$ for UR1080.

However, from the macroscopic viewpoint as a sealing gasket, the temperature dependence of $E^{\prime}$ for TOYO-UR and UR1080 was almost identical. Thus, it can be claimed that the existence of microcapsules and fillers did not strongly impact the mechanical properties of the urethane polymer. The additive-containing UR1080 exhibited a rubbery plateau with a low modulus in the wide temperature range from -10 to $120^{\circ} \mathrm{C}$. Although $E^{\prime}$ slightly decreased at the higher temperature region of the rubbery plateau, a low and constant modulus of UR1080 in the entire temperature region was intriguing for its use as a sealing gasket.

Figure 8 shows the JIS A hardness and compression set for the PVC-based elastomer, styrene-ethylene-butadiene-rubber, EPR and TOYO-UR. All of the samples employed were additive-free. The data for UR1080 are also displayed. Both the PVC-based elastomer and styrene-ethylene-butadiene-rubber exhibited similar properties: hardness of 60 to 70 and compression set of 50 to $55 \%$. The hardness and 


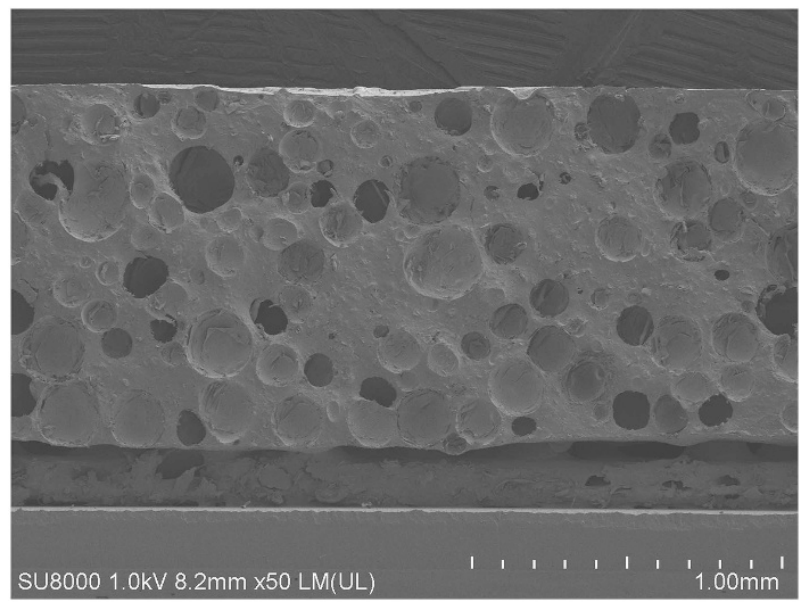

Figure 6 Scanning electron microscope image of the cross-section of the urethane sealing gasket (UR1080).

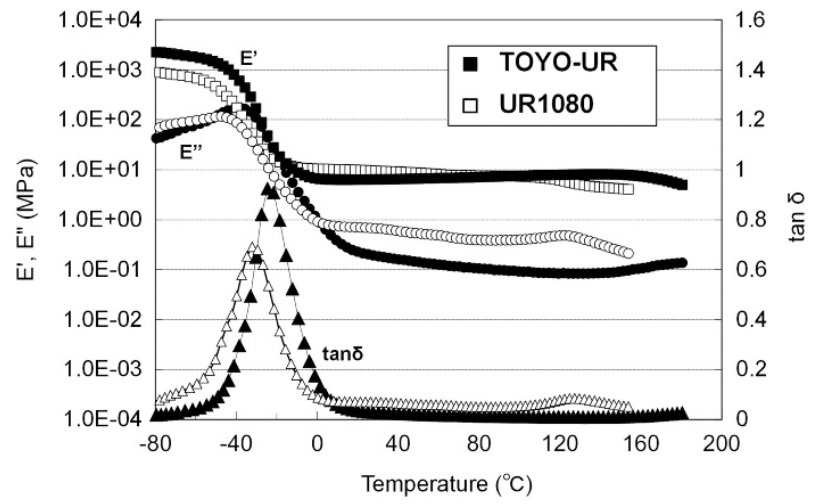

Figure 7 Dynamic viscoelastic properties as a function of temperature for the urethane-based polymer (TOYO-UR) and the urethane sealing gasket (UR1080) at $1 \mathrm{~Hz}$.

compression set of EPR were 90 and $80 \%$, respectively, meaning that the hardness and creep deformation of EPR were too high for it to be used as a sealing material. In the case of the urethane-based polymer, although the hardness was 60 , which was similar to that of the PVCbased elastomer and styrene-ethylene-butadiene-rubber, the compression set was the lowest (5\% or less) among the samples employed. This makes it clear that a crosslinked structure using the trifunctional polyol (F-510) could be successfully introduced into the TOYO-UR.

By combining the heat-expandable microcapsules with TOYO-UR, the hardness and compression set decreased and increased in comparison with the base polymer, respectively, as shown for UR1080 in Figure 8. This resulted in an increase in the flexibility of the urethane, which was appropriate for a sealing gasket. In addition, the contact area of sealing between the glass mouth and the sealant increased as a result of suitable creep deformation. These favorable effects were because of the foaming by the microcapsules, DU-092120 , which exerted no influence on the polymer structure, such as the crosslinked structure, of the base polymer matrix. The microcapsules possessed an outer shell structure made of AN and MAN, which have excellent gas barrier properties. When the sealing gasket was formed by heating, the expansion of the microcapsules and the reaction of the urethane raw material simultaneously occurred. As a consequence, a urethane-based polymer with a three-dimensional network structure

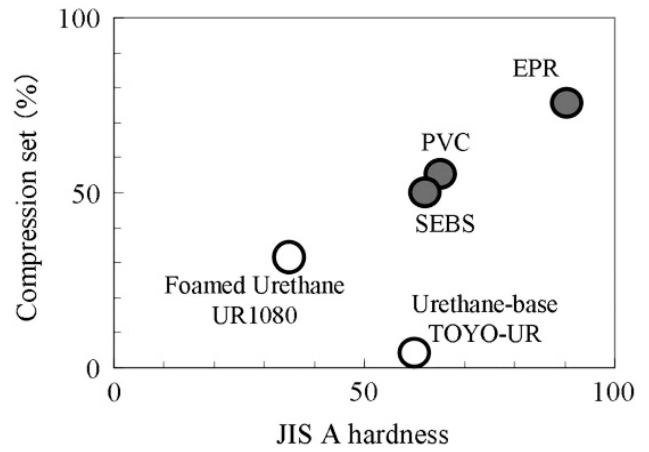

Figure 8 JIS A hardness and compression set on various types of base polymers for sealing gaskets and the urethane sealing gasket (UR1080).

Table 4 Comparison of the sealing and opening properties between UR1080 and a PVC-based gasket formulated with additives on closures of $53 \mathrm{~mm}$ in diameter

\begin{tabular}{lcc}
\hline Sealing gasket & UR1080 & PVC-based \\
\hline Specific gravity & 0.80 & Non-foamed \\
Opening torque (Nm) & & \\
Aging at $23^{\circ} \mathrm{C}$ & 1.7 & 2.5 \\
Aging at $40^{\circ} \mathrm{C}$ & 2.1 & 3.2 \\
Lateral force resistance (N) & 450 & 550 \\
Impact test & No leakage, no absorption \\
Unbalanced loading test & No leakage, no absorption \\
\hline
\end{tabular}

was formed. It is considered that the presence of the microcapsules resulted in a lower hardness (easy deformability) and a larger compression set. Additionally, the matrix with the crosslinked structure contributed to less stress relaxation and improved deformation recovery.

The development of UR1080 with excellent sealing characteristics was described above. However, a problem of incorporating properties that support easier release when the seal is disengaged (opening the bottle) but compromise the sealing property still remained. Because the dynamic friction coefficient of TOYO-UR was 1.7, which was quite large, it must be reduced. Our strategy to do so and to confer excellent opening properties was to use lubricants and others. Table 4 summarizes the comparison of the sealing and opening properties of UR1080 and a PVC-based sealing gasket with additives.

Although the specific gravity of UR1080 formed on closures is $0.80 \mathrm{~g} \mathrm{~cm}^{-3}$, a PVC-based sealing gasket is a non-foamed type. In this study, the opening properties refer to properties that support easier release when the seal is disengaged (opening the bottle). These were discussed on the basis of the opening torque after 6 months of storage at 23 and $40^{\circ} \mathrm{C}$. They were better for UR1080 than for the PVC-based sealing gasket.

For sealing properties, suggested tests such as of the lateral force resistance, impact and unbalanced loading tests were performed. The results are shown in Table 4. The lateral force resistance of UR1080 was slightly lower than that of the PVC-based one, although both numbers fully conformed to practical use. The results of the impact test and the unbalanced loading test for the two gaskets were comparable. In general, the sealing and opening properties were compensatory in nature. Thus, because the opening torque preceded, the lateral force resistance became slightly lower. 
The closure performance was the result of one hundred measurements. The opening property was a very delicate matter. In industrial products that are delivered to the market in millions or tens of millions, some may have an abnormally high opening torque because of slight differences in production conditions. To address this issue, we examined the causes of high opening torque in closures and the mechanism of generating an excellent opening property below.

Figure 9 shows the scanning electron microscopy images of the crosssection of an abnormal product of UR1080 with high opening torque (left) and a normal product with a good opening property (right). The specimens were first washed with THF to remove the additives. The surface with dark appearance was where the urethane-based polymer was exposed to the surface. The bright white region was where the surface was covered with talc. The talc used here consisted of a scale-like silicate mineral with a particle size of $20 \mu \mathrm{m}$, and its main component was magnesium hydroxide and silicate. Elemental analysis of $\mathrm{Mg}$, Si and C confirmed that the white part was the talc. The surface exposure of the polar urethane-based polymer increased the affinity between the sealing gasket and the glass mouth, thereby resulting in a less favorable opening property. Thus, to achieve a good opening property, it is important to cover the UR1080 surface with talc. A slip property originated from the lubricants composed of aliphatic acid amides and silicone oils, which were blended with (or into) UR1080. Because the lubricants, especially the aliphatic acid amide component, can be highly compatible with TOYO-UR, it is likely that the occurrence of high opening torque was attributed to a lack of lubricant bleeding. When temperature increased, the opening torque increased, probably because the compatibility between them increased with increasing temperature. Interestingly, it was found that if the surface coverage of the talc increased, the bleeding amount of lubricants also increased.

Figure 10 shows the dispersion state of the additives in the urethane compound observed by optical microscopy. Aggregates of $\sim 100 \mu \mathrm{m}$

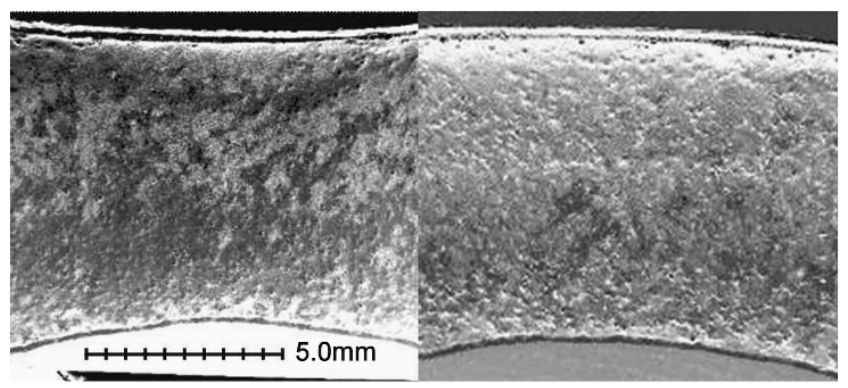

Figure 9 Surface morphology of the urethane sealing gasket (UR1080). were dispersed in the compound composed of the polyisocyanate and polyols. The aggregates mainly consisted of aliphatic acid amides, silicon oils, titanium oxide and talc. Among the components, the aliphatic acid amides and silicon oils were necessary for the formation of aggregates. The aggregates could be easily formed as their amounts increased. Moreover, the aggregate formation was affected by temperature; for instance, aggregates readily formed at $48{ }^{\circ} \mathrm{C}$ or less, whereas no aggregates formed above $50^{\circ} \mathrm{C}$. They disappeared when they were heated to $55^{\circ} \mathrm{C}$ or higher. The sealing material with aggregates was lined and cured and exhibited a good opening property, whereas the one without aggregates had a high opening torque. The reason for the difference is that the melting of the aggregates resulted in bleeding out of the aggregate constituents to the surface of the closure, meaning that the gasket surface was covered with lubricant along with talc.

The mechanism of the slip property was correlated to the surface localization of the lubricants. In preparing materials as sealing gaskets, the compatibility between the base polymer and the lubricants is of utmost concern. When the lubricants migrate to the surface, this compatibility should remain even at different temperatures. To this end, closure products were prepared after aging at a temperature that promoted the surface localization of the lubricants. Likewise, additional components were used to control the compatibility between the base polymer and the lubricants. However, the mechanism of the slip property proposed in this study was different from the conventional hypothesis. We maintain that the lubricant aggregates including talc floated on the surface of the compound, which melted during thermal curing, thereby resulting in coverage of the talc surface with lubricants. This led to the manifestation of the slip property.

\section{CONCLUSIONS}

A urethane-based polymer (TOYO-UR) having a rubbery plateau with a low modulus over a wide temperature range was developed as an ideal sealing material. TOYO-UR developed here was composed of an aliphatic diisocyanate adduct (C-2612), bifunctional polyols (PTG-1000 SN and P-1010NF) and a trifunctional polyol (F-510). The MW between crosslinking points $\left(M_{\mathrm{c}}\right)$ was estimated to be $\sim 5300 \mathrm{~g} \mathrm{~mol}^{-1}$. Sealing gaskets were developed by incorporating additives into TOYOUR as follows: blended talc as a filler; fatty acid amides and silicones as lubricants; and heat-expandable microcapsules with an outer shell that consisted of AN and MAN as a blowing agent. The resulting material, referred to in this study as UR1080, exhibited ideal physical properties suitable for sealing applications, such as a constant and low modulus over a wide temperature range (between -10 and $120^{\circ} \mathrm{C}$ ), JIS A hardness of 35, compression set of $30 \%$ and Young's modulus of $1.5 \mathrm{MPa}$ at room temperature. These properties supported UR1080 as

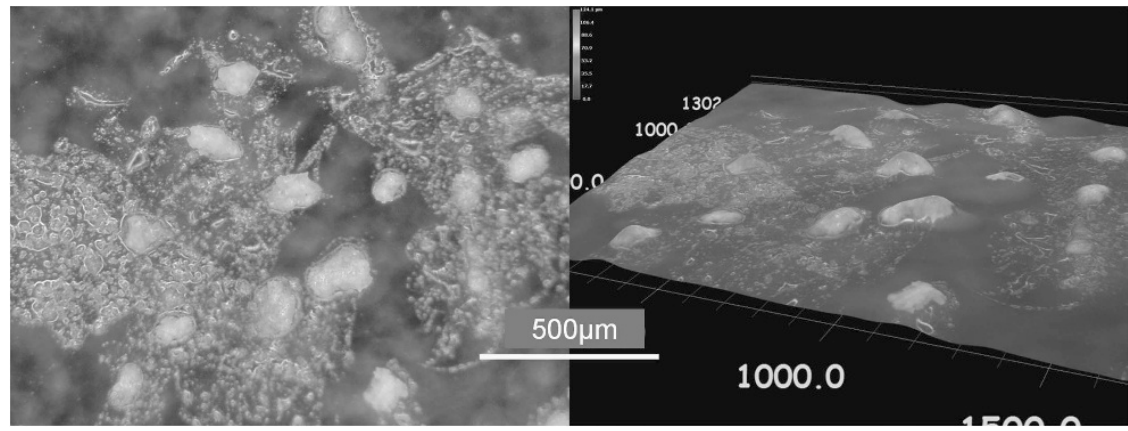

Figure 10 Dispersion state of the additives in the urethane compound. A full color version of this figure is available at Polymer Journal online. 
an excellent alternative sealing gasket because it possessed remarkable sealing and opening properties that are desired for such application. We finally determined how stable and easy-opening properties could be achieved in the sealing gaskets used in metal closures. This was made possible by the aggregates composed of fatty acid amides, silicones and talc that first bled out to the surface of UR1080 and then were melted as a result of rising temperature. This led to the coverage of the surface of the sealing gaskets with constituents that acted as lubricants, as well as talc.

\section{ACKNOWLEDGEMENTS}

We acknowledge the contribution of Mr. Hiroei Yokota at Nippon Polyurethane Industry and Mr. Hiroyuki Tsuchiya at Fukuoka Packing in the development of the urethane-based polymer and of the additives formulation, respectively. Employees of Nippon Closures (Japan Crown Cork), Toyo Seikan, Aohata and Kurary who have worked in the practical use of the urethane-based polymer are also acknowledged. Additionally, individuals from Corporate R\&D, Toyo Seikan Group Holdings, who supported the pre-development of the acrylic plastisol until the completion of the urethane sealing gasket are also recognized.

1 Nakazawa, H., Miyazaki, Y., Masukawa, K., Hirayama, K. \& Fujimaki, T. Study on endocrine disrupting chemicals in cap sealing for bottled foods, Report of Health Science Research Grants in 1999 (Consumer Safety Research Program) 93-97 (1999).

2 Hammarling, L., Gustavsson, H., Svensson, K., Karlsson, S. \& Oskarsson, A. Migration of epoxidized soya bean oil from plasticized PVC gaskets into baby food. Food Add. Contam. 15, 203-208 (1998).

3 Fantoni, L. \& Simoneau, C. European survey of contamination of homogenized baby food by epoxidized soybean oil migration from plasticized PVC gaskets. Food Add. Contam. 20, 1087-1096 (2003).

4 AFC Opinion of the scientific panel on food additives, flavourings, processing aids and materials in contact with food (AFC) on a request from the Commission related to the use of epoxidised soybean oil in food contact materials. EFSA J. 64, 1-17 (2004)

5 Frankhauser-Noti, A., Fiselier, K., Biedermann, S., Biedermann, M., Grob, K., Armellini, F., Rieger, K. \& Skjevrak, I. Epoxidised soybean oil (ESBO) migrating from the gaskets of lids into food packed in glass jars. Eur. Food Res. Tech. 221, 416-422 (2005)

6 Frankhauser-Noti, A. \& Grob, K. Migration of plasticizers from PVC gaskets of lids for glass jars into oily foods. Trends Food Sci. Technol. 17, 105-112 (2006).

7 Frankhauser-Noti, A, Biedermann-Bern, S \& Grob, K PVC plasticizers/additives migrating from the gaskets of metal closures into oily food: Swiss market survey June 2005. Eur. Food Res. Tech. 223, 447-453 (2006).

8 Tsumura, Y., Kaihara, A., Ishimitsu, S., Yoshii, K. \& Tonogai, Y. Contents of plasticizers in cap-sealing for bottled food and their migration into food. J. Food Hyg. Soc. Japan 43, 377-384 (2002)
9 Kanno, S., Kawamura, Y., Mutsuga, M. \& Tanamoto, K. Survey of epoxidised soybean oil in cap sealing for bottled foods. J. Food Hyg. Soc. Japan 47, 196-199 (2006).

10 Kawamura, Y., Kanno, S., Mutsuga, M. \& Tanamoto, K. Determination of epoxidized soybean oil in bottled foods. J. Food Hyg. Soc. Japan 47, 243-248 (2006).

11 Takemura, Y. Development status on thermoplastics for post soft-polyvinylchloride materials. Eng. Mater 46, 28-32 (1998).

12 Okuri, Y. \& Nakata, Y. Environmental response in automotive adhesives. J. Adhesion Soc. Japan 22, 62-66 (2002).

13 Moriga, T., Kojima, S. \& Kobayashi, S. Plastisol composition, US Patent 5441994 (1995).

14 Moriga, T., Kojima, S., Kobayashi, S., Obu, Y. \& Odajima, S. Acrylic plastisol adhesion structure, US Patent 5677053 (1997).

15 Moriga, T., Kojima, S., Nagase, T. \& Kobayashi, T. Cap seal composition, Japanese Patent 2674947 (1997).

16 Moriga, T., Kojima, S. \& Kobayashi, S. Acrylic plastisol composition with excellent creep resistance, Japanese Patent 2739805 (1998).

17 Moriga, T., Yokota, H., Tsuchida, T. \& Yano, N. Sealing gasket for closure and process for production of closure using the same, Japanese Patent 2674947 (2007).

18 Moriga, T., Yokota, H., Tsuchida, T. \& Yano, N. Sealing gasket for closure and process for production of closure using the same, US Patent 6872796 (2005).

19 Japan Crown Cork Co., Ltd., Inventory of Effective Food Contact Substance Notifications (U.S. Food and Drug Administration), FCS No. 425 (2004).

20 Shirasaka, H., Yamashita, M., Inagaki, T., Inoue, S. \& Okamoto, H. Elastomeric properties of polyurethane prepared from PTMG regulated molecular weight distribution. Nippon Gomu Kyokaishi 72, 123-129 (1999).

21 Chen, W., Frisch, K. C., Donald, J. K. \& Wong, S. Effect of soft segment molecular weight and 3-methyl side group on microstructural separation in polyurethane elastomers. J. M. S. Pure Appl. Chem. A29, 567-587 (1992).

22 Brochure of Japan Fillite Co., Ltd. EXPANCEL ${ }^{\circledR}$ MICROSPHERES (1999).

23 Moriga, T., Aoyama, N., Tsuchiya, H. \& Komaki, T. Cap sealing member, Japanese Patent 3860509 (2006).

24 Moriga, T., Aoyama, N., Tsuchiya, H. \& Komaki, T. Sealing member for a cap featuring excellent safety and environmental friendliness, and metal cap, US Patent 6878449 (2005).

25 Moriga, T., Aoyama, N., Tsuchiya, H., Komaki, T. \& Fujisawa, K Cap sealing member, Japanese Patent 3810346 (2006)

26 Moriga, T. \& Aoyama, N. Metal closure, Japanese Patent 4068831 (2008).

27 Yokoyama, T., Hiraoka, K. \& Li, X.D. The effect of the structure of network junction point on the viscoelasticity of model polyurethane networks. Nippon Gomu Kyokaishi 66, 98-104 (1993)

28 Krevelen, D.W. \& Nijenhuis, K. Mechanical Properties of Solid Polymers, Properties of Polymers, Ch. 13, 383-405 (Elsevier, 2008).

29 Toluene Diisocyanate (TDI) and Toluenediamine(TDA): Evidence of Carcinogenicity (1989) http://www.cdc.gov/niosh/docs/90-101/

30 Prisacariu, C., Scortanu, E. \& Agapie, B. New insights into polyurethane elastomers obtained by changing the polyaddition procedures. Proceedings of the World Congress on Engineering 2011 Vol III, 2178-2183 (2011).

31 Treloar, L.R.G. The Physics of Rubber Elasticity (Oxford, 2005).

32 Furukawa, M. Science and technology of polyurethanes. II Analytical methods for polyurethanes. Nippon Gomu Kyokaishi 84, 124-131 (2011)

33 Iwata K. (ed.) Polyurethane Handbook (Nikkan Kogyo Shinbun, 1987).

34 Murayama, S. Basis on polyurethane. J. Adhesion Soc. Japan 31, 12-18 (2011).

Supplementary Information accompanies the paper on Polymer Journal website (http://www.nature.com/pj) 